\title{
Recent Progress of Cu-Catalyzed Azide-Alkyne Cycloaddition Reactions (CuAAC) in Sustainable Solvents: Glycerol, Deep Eutectic Solvents, and Aqueous Media
}

\author{
Noel Nebra ${ }^{1, *(\mathbb{D}) \text { and Joaquín García-Álvarez }}{ }^{2, *(\mathbb{D})}$ \\ 1 UPS, CNRS, LHFA UMR 5069, Université de Toulouse, 118 Route de Narbonne, 31062 Toulouse, France \\ 2 Departamento de Química Orgánica e Inorgánica, Instituto Universitario de Química Organometálica \\ “Enrique Moles" (IUQOEM), Facultad de Química, Universidad de Oviedo, E-33071 Oviedo, Spain \\ * Correspondence: nebra-muniz@chimie.ups-tlse.fr (N.N.); garciajoaquin@uniovi.es (J.G.-Á.)
}

Academic Editor: Alejandro Baeza Carratalá

Received: 7 April 2020; Accepted: 23 April 2020; Published: 26 April 2020

\begin{abstract}
This mini-review presents a general overview of the progress achieved during the last decade on the amalgamation of CuAAC processes (copper-catalyzed azide-alkyne cycloaddition) with the employment of sustainable solvents as reaction media. In most of the presented examples, the use of water, glycerol $(G l y)$, or deep eutectic solvents $(D E S s)$ as non-conventional reaction media allowed not only to recycle the catalytic system (thus reducing the amount of the copper catalyst needed per mole of substrate), but also to achieve higher conversions and selectivities when compared with the reaction promoted in hazardous and volatile organic solvents (VOCs). Moreover, the use of the aforementioned green solvents also permits the improvement of the overall sustainability of the $\mathrm{Cu}$-catalyzed 1,3-dipolar cycloaddition process, thus fulfilling several important principles of green chemistry.
\end{abstract}

Keywords: CuAAC; water; glycerol; deep eutectic solvents; cycloadditions; green chemistry; metal-catalysis

\section{Introduction}

The employment of copper catalysts, as opposed to the use of stoichiometric amounts of other typical promoters (like Brønsted acids, bases, radicals, etc.), has permitted the discovery of a plethora of new synthetic protocols within the toolbox of organic chemists [1]. Thus, the introduction of these $\mathrm{Cu}$-catalyzed methodologies in different fields (ranging from asymmetric synthesis [2] to cross-coupling processes [3]) paved the way for the convenient and successful synthesis of high value-added organic products (like for example agrochemical or pharmaceutical commodities). Moreover, $\mathrm{Cu}$ is usually considered as "the metal of choice" in organic transformations being catalyzed by coinage metals [4]. This is due to the following properties: (i) it is an earth-crust abundant first row transition metal, and thus cheaper than other second or third row precious metals (like for example, $\mathrm{Pd}, \mathrm{Pt}, \mathrm{Rh}, \mathrm{Ir}$, or $\mathrm{Au}$ ); (ii) it presents a wide variety of oxidations states $(\mathrm{Cu}(0), \mathrm{Cu}(\mathrm{I}), \mathrm{Cu}(\mathrm{II})$ or even $\mathrm{Cu}(\mathrm{III}))$ with different coordination environments (for example, linear, square planar or tetrahedral); (iii) it accommodates both hard or soft donor ligands in its coordination sphere, and forms $\sigma$ - or/and $\pi$-interactions with unsaturated organic substrates (like alkenes or alkynes); (iv) it is an important metal in Biology (present in enzymes and proteins) [5], also being the less toxic first row metal (together with Fe); and (v) it is active under both homogenous or heterogeneous [6] conditions. 
These advantageous properties make copper catalysts suitable candidates to be used in organic synthesis, thus being not surprising to observe a positive slope in the tendency of the number of publications on this topic since 2010 (see Figure 1).

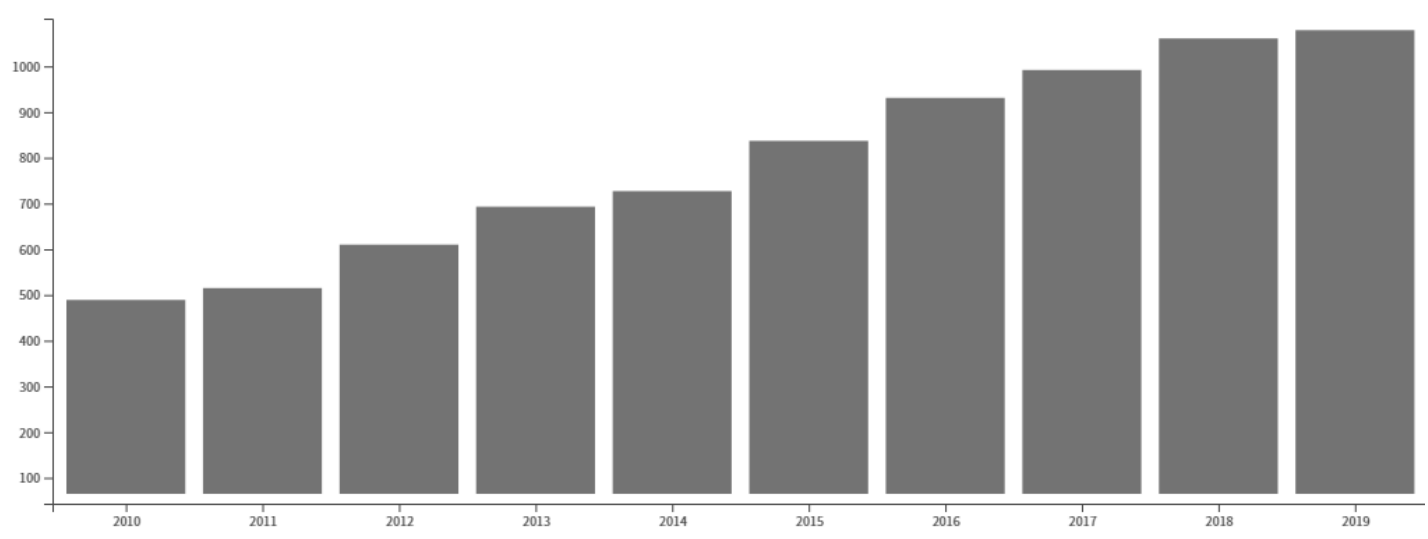

Figure 1. Articles related with the topic "Cu-catalyzed organic reactions" obtained from Web of Science.

With no doubt, one of the most prolific and successful applications of copper catalysts in organic synthesis are the so-called $\mathrm{CuAAC}$ reactions (Copper-catalyzed azide-alkyne cycloaddition) that belong to the family of "click chemistry" procedures. First coined by Sharpless back in 2001 [7], this concept appeared to design thermodynamically driven chemical processes that allow the direct synthesis of highly complex organic architectures by starting from simple and readily-available organic building blocks. Moreover, to be considered "click", these reactions should be in accordance with the following principles: (i) tolerance of moisture and oxygen (i.e., standard bench conditions); (ii) "solventless" conditions or using a benign solvent is required; (iii) the isolation of the final products must be straightforward (i.e., nearly quantitative and without tedious steps of purification); and (iv) should occur with total regio- and stereoselectivity. In this sense, the aforementioned CuAAC (independently reported by the groups of Meldal [8] and Sharpless [9]) is considered as one of the most genuine examples of this "click chemistry" concept. This major discovery is based on the previously reported Huisgen cycloaddition, a synthetic tool that proceeds slowly under thermal conditions giving rise to a mixture of the corresponding 1,4- and 1,5-disubstituted 1,2,3-triazoles (see Scheme 1a) [10]. Meldal and Sharpless found that just by simple addition of a copper catalyst, this atom economic 1,3-dipolar cycloaddition leads to the 1,4-triazole as the only product of reaction, thus fulfilling now the principles of "click chemistry" (see Scheme 1b). Although either metal-free [11] or Ag-[12], Ru-[13], Ir-[14] and Ni-catalyzed [15] cycloadditions of azides and alkynes have been reported, only Cu-catalysts have found a wide chemical application [16], like: (i) drug discovery and development; (ii) synthesis of peptides, carbohydrate-based molecules or nucleosides/nucleotides; (iii) polymer science; and (iv) macrocyclic chemistry.

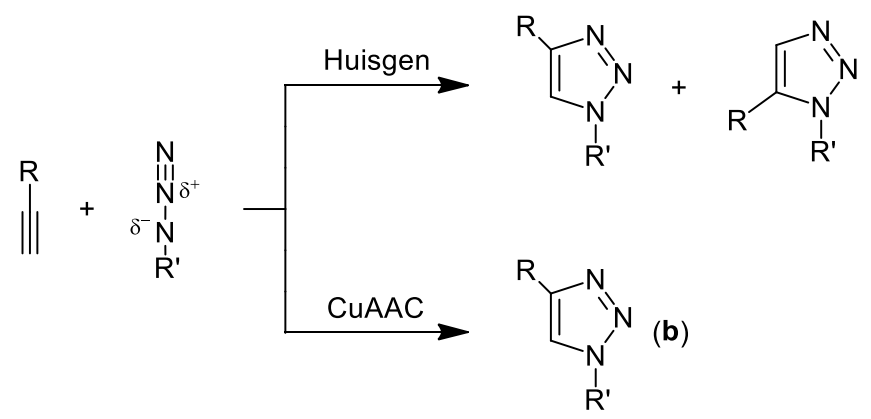

Scheme 1. Cu-catalyzed cycloaddition of azides and terminal alkynes (CuAAC; (b)) vs. thermodynamically driven Huisgen cycloaddition (a). 
In accordance with the originally coined definition of "click chemistry" and the requirements for a chemical process to be considered "click" [7], the desired transformation should take place under solventless reaction conditions. However, it is now well-established that solvents usually present a concomitant positive effect in the overall synthetic process, the so-called "solvent effect" [17]. This unquestionable positive solvent effect is generally associated with the capability of solvents to: (i) stabilize both metallic catalysts and transient intermediates; (ii) reduce unwanted side reactions; and (iii) help in the control of the heat flow. Thus, in most cases, the best option to work under strict "click" conditions is to replace traditional and hazardous volatile organic solvents (VOCs) with an environmentally friendly reaction media. In theory, these solvents to be considered green should be [18]: (i) biorenewable and biodegradable; (ii) cheap and easily available; (iii) non-toxic for both the environment and the human beings; (iv) safe (non-flammable, low vapor pressure); and (v) capable of dissolving a wide range of chemicals. With these strict requirements in mind, it is not surprising to find that the pool of available green and sustainable solvents is quite narrow, being the most typical examples: (i) water [19]; (ii) biomass derived solvents (like glycerol [20], $\gamma$-valerolactone [21], 2-methyl-THF [22] or lactic acid [23]); or (iii) Deep Eutectic Solvents (DESs) [24]. Thus, this mini-review focuses on the recent progress achieved on 1,3-dipolar cycloadditions of azides and alkynes mainly using molecular Cu-catalysts (CuAAC) that take place in glycerol (Gly), Deep Eutectic Solvents (DESs), or water as sustainable reaction media.

\section{Cu-Catalyzed 1,3-Dipolar Cycloaddition of Azides and Alkynes (CuAAC) in Glycerol (Gly)}

As previously commented, the use of green solvents is mandatory for the development of $\mathrm{CuAAC}$ processes under "click" conditions [7]. In this regard, biomass derived solvents are playing a pivotal role in the substitution of traditional volatile and hazardous organic solvents (VOCs) by greener, safer and sustainable reaction media [25]. Among all biomass-derived solvents, glycerol (Gly, which is obtained as a major by-product from the biodiesel industry [26] or from the conversion of lignocellulose or cellulose into other chemical compounds [27]), has received great attention from the synthetic community as a plausible candidate for the replacement of $V O C$ solvents in organic synthesis [20]. Moreover, due to its: (i) inherent physicochemical properties (low toxicity, non-flammability, high polarity, and boiling point); (ii) capability to dissolve both inorganic and organic compounds; (iii) easily separation of organic products and catalysts from the reaction media (that allows catalyst recycling); and (iv) previously reported competence to enhance both selectivity and productivity of given chemical reactions [28], glycerol is considered one of the archetypical prototypes of green and sustainable solvents. In this sense, García-Álvarez and co-workers [29] paved the way to follow in the CuAAC reaction using CuI/glycerol as catalytic system. This unprecedented combination promoted the Huisgen cycloaddition of organic azides with either terminal or internal 1-iodoalkynes at room temperature using low catalyst loadings $(1 \mathrm{~mol} \%$ in $\mathrm{Cu}$ ), in the presence of air and in the absence of any external base (Scheme 2a). In this work, the authors were able to recycle the aforementioned catalytic system up to six consecutives cycles and avoid the use of $V O C$ solvents, as straightforward isolation of the desired triazoles was accomplished by simple filtration of the reaction crude. For comparison, the catalytic activity of $\mathrm{CuI}$ in a conventional and hazardous volatile organic solvent (i.e., $\mathrm{CH}_{2} \mathrm{Cl}_{2}$ ) was also evaluated and longer reaction times $(24 \mathrm{~h})$ were needed to achieve quantitative conversions $(99 \%)$. This example supports clearly our previous affirmation which assessed the importance of green solvents in the design of a synthetic chemical process, thus disclosing a new example of an accelerated organic reaction in environmentally friendly reaction media.

More recently, Schoffstall and co-workers have employed the same catalytic system (CuI/glycerol) for the synthesis of 1,2,3-triazoles containing fluorinated groups (Scheme 2b) [30]. In the same year (2019), Bez et al. proved the beneficial effect of L-proline as a ligand to improve the catalytic activity of $\mathrm{CuI}$ in CuAAC cycloadditions using glycerol as solvent [31]. This methodology was successfully applied to the synthesis of possible pharmacologically active heterocyclic compounds like, for example, those derived from propargylated dihydroartemisinin (Scheme 2c). 

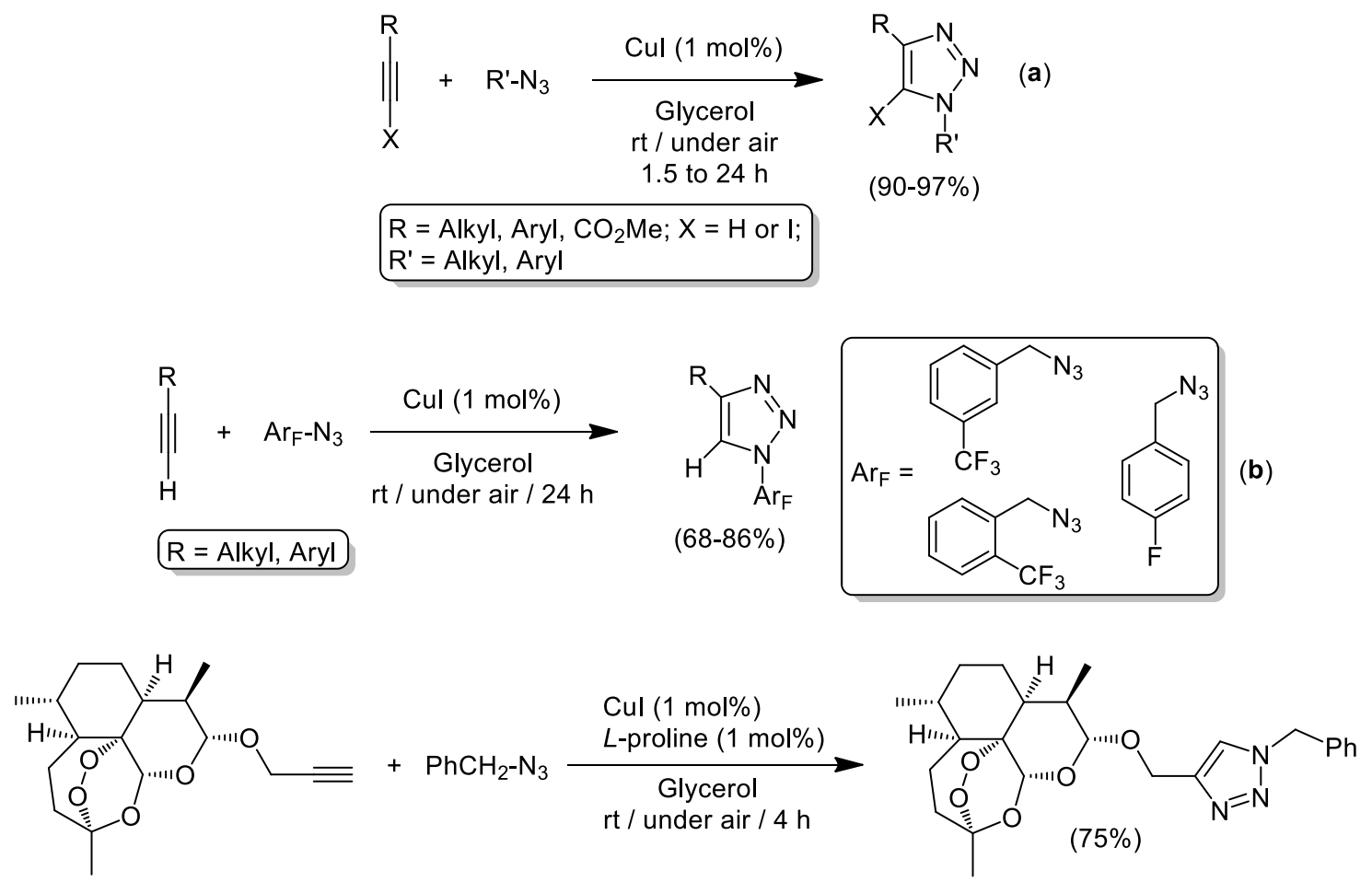

Scheme 2. Cycloaddition of azides and alkynes (CuAAC) in pure glycerol as solvent catalyzed by $\mathrm{CuI}$ $(\mathbf{a}, \mathbf{b})$ or the mixture CuI/L-proline (c).

Contemporaneously to and independent of the pioneering work by García-Álvarez et al., Gómez et al. demonstrated that glycerol by itself (without the help of any transition metal catalysts) is able to promote the Huisgen reaction of internal alkynes and organic azides when employing both microwave irradiation and thermal treatment (warming up to $100^{\circ} \mathrm{C}$ ) [32,33] (Scheme 3a). For the case of unsymmetrically substituted alkynes, the authors observed the formation of an almost equimolar mixture of both regioisomers.

After this seminal work, the same authors reported the possibility to use $\mathrm{Cu}(\mathrm{I})$-based-nanoparticles as highly efficient catalyst for the cycloaddition of organic azides and terminal alkynes [34]. In this work, Gómez, Pericàs and co-workers studied deeply the role of different aliphatic and aromatic amines as co-catalysts for $\mathrm{CuAAC}$ reactions finding that an excess of oleylamine ( $5 \mathrm{~mol} \%$ ) favors the in-situ generation of Cu-nanoparticles when using $\mathrm{CuI}(1 \mathrm{~mol} \%)$ as pre-catalyst (see Scheme $3 b)$. Remarkably, the formation of these $\mathrm{Cu}(\mathrm{I})$-nanoparticles was also observed in other highly polar solvents like water or dioxane. More recently, the Gómez group has also reported the three-component version of AAC cycloadditions (by using the mixture $\mathrm{NaN}_{3} / \mathrm{PhCH}_{2} \mathrm{Br}$ as a source of benzyl azide) in pure glycerol (at $80^{\circ} \mathrm{C}$ ) by employing small and well-dispersed zerovalent PdCu bimetallic nanoparticles (PdCuNPs, mean diameter, ca. 3-4 nm) stabilized by polyvinylpyrrolidone (PVP) as catalysts (see Scheme 3c) [35].

Apart from glycerol, other biosourced alcohol-type solvents like polyethylene glycol (PEG) have been employed in CuAAC reactions [36-43]. In this sense, PEG-400 has been used as environmentally friendly and inexpensive solvent thanks to its: (i) low toxicity; (ii) non-volatility; (iii) recyclability and biodegradability; (iv) thermal stability; and (v) commercial availability [44]. Thus, the first work in this field was reported back in 2006 by Sreedhar and co-workers who describe an efficient and reliable CuI-catalyzed three-component reaction that employs terminal alkynes, $\mathrm{NaN}_{3}$ and Baylis-Hillman acetates as starting materials for the high-yielding synthesis of 1,4-disubtitutes triazoles in PEG at room temperature (see Scheme 4) [36]. At this point it is important to note that better yields of the desired triazoles were obtained when hazardous and volatile organic solvents (like THF, $\mathrm{CH}_{3} \mathrm{CN}$ or DMSO) were replaced by PEG. After this pioneering work, the aforementioned CuI/PEG catalytic system was applied for the synthesis of: (i) $\beta$-hydroxy 
or N-tosylamino 1,2,3-triazole scaffolds [37]; (ii) biologically active bis(indolyl)methane derivatized 1,4-disubstituted 1,2,3-bistriazoles [38]; (iii) 1,4-diaryl-1H-1,2,3-triazoles by reaction of diaryliodonium salts, $\mathrm{NaN}_{3}$ and terminal alkynes [39]; and (iv) 4-substituted-1,2,3-triazole analogues of azole antifungal agents [40]. Not only $\mathrm{CuI}$, but also the archetypical catalytic mixture $\mathrm{CuSO}_{4} \cdot 5 \mathrm{H}_{2} \mathrm{O} /$ ascorbic acid has been fruitfully applied in CuAAC processes devoted to the synthesis of 1,2,3-triazole tethered benzimidazo[1,2-a]quinolines [41] or $1 \mathrm{H}$-1,2,3-triazole tethered pyrazolo[3,4-b]pyridin-6(7H)-ones [42] by employing PEG as sustainable solvent at high temperatures (100-120 $\left.{ }^{\circ} \mathrm{C}\right)$. Finally, Astruc and co-workers nicely described the use of PEG as stabilizer for copper nanoparticles (CuNP) which are catalytically active in $\mathrm{CuAAC}$ processes in a mixture water/ ${ }^{t} \mathrm{BuOH}$ and in the presence of air [43].
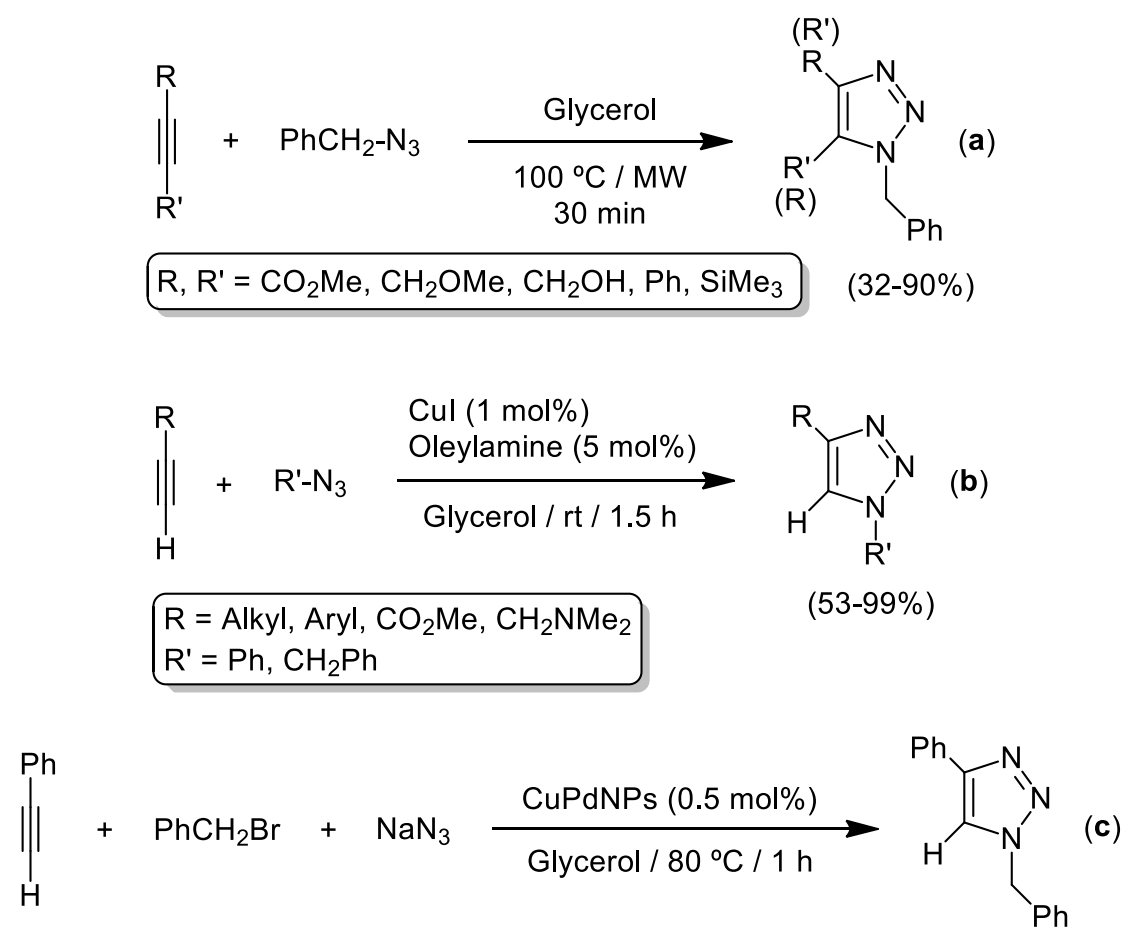

Scheme 3. Cycloaddition of azides and alkynes (AAC) in pure glycerol as solvent reported by the groups of Gómez and Pericàs which employed microwaves (a), CuI/oleylamine (b) or Cu/Pd metallic nanoparticles (c) as promoters.

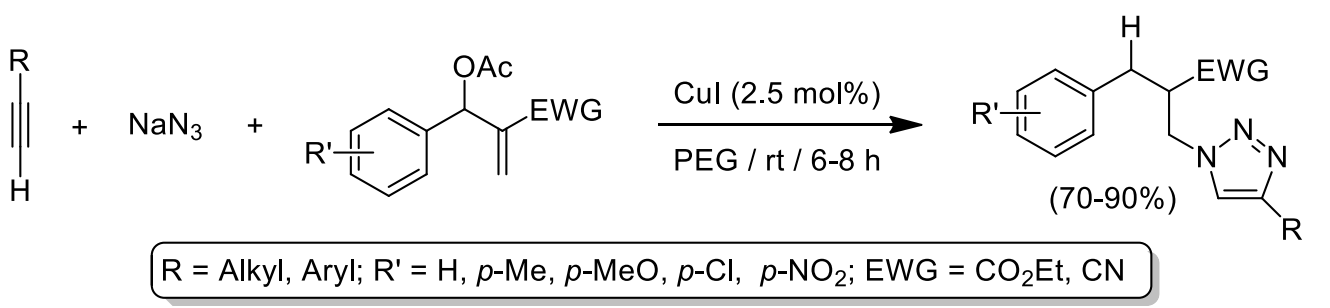

Scheme 4. CuI-catalyzed synthesis of 1,4-disubstituted 1,2,3-triazoles starting from Baylis-Hillman acetates, terminal alkynes and sodium azide using PEG as sustainable solvent.

\section{Cu-Catalyzed 1,3-Dipolar Cycloaddition of Azides and Alkynes (CuAAC) in Deep Eutectic Solvents (DESs)}

Deep Eutectic Solvents (DESs) [24] are defined as the result of the combination of two (or even three) chemical substances which are able to form a new eutectic mixture (with a melting point below that of its individual components) through the formation of a tridimensional hydrogen-bond network [45]. One of the most commonly used components in the synthesis of these eutectic mixtures is the biorenewable and biodegradable ammonium salt choline chloride ( $\mathrm{ChCl}$, vitamin B4) [46]. 
In combination with different hydrogen bond donors like: (i) naturally occurring polyols (glycerol, ethylene glycol or carbohydrates) [47], (ii) biorenewable organic acids [48], or (iii) urea [49]; choline chloride $(\mathrm{ChCl})$ is able to form sustainable and liquid eutectic mixtures which have found application in a plethora of different chemical fields [50-52]. As expected, and when the concept of Deep Eutectic Solvents crossed the field of traditional organic synthesis, CuAAC was also assayed in these sustainable reaction media. In this sense, König et al. were the real pioneers in this field back in 2009 by reporting the CuI-catalyzed cycloaddition of phenylacetylene with benzyl azide for the synthesis of the archetypical 1,4-disubstituted 1,2,3-triazoles [53]. However, it should be mentioned that: (i) quite drastic conditions $\left(85^{\circ} \mathrm{C}, 5 \mathrm{~mol} \%\right.$ of $\mathrm{CuI}$ and $5 \mathrm{~h}$ of reaction) were needed to obtain the desired triazole in high yield (93\%, see Scheme 5a), and (ii) no recycling studies of the catalytic system in DESs were reported. In contrast, employing a catalytic system based on the combination of $\mathrm{CuSO}_{4}$ with sodium ascorbate as reducing agent (typically used in other $\mathrm{CuAAC}$ reactions), the yield of the desired triazole only reached $84 \%$. The use of the ternary eutectic mixture $D$-sorbitol/urea/ $\mathrm{NH}_{4} \mathrm{Cl}$, as sustainable solvent, also allowed the in-situ synthesis of the benzyl azide (starting from $\mathrm{PhCH}_{2} \mathrm{Br}$ and $\mathrm{NaN}_{3}$ ) in the corresponding three-component version of the CuAAC process. Interestingly, the aforementioned $\mathrm{CuAAC}$ process proceeded slightly better when the $L$-carnitine-based eutectic mixture $L$-carnitine/Urea was used as sustainable solvent (see Scheme $5 b$ ). This experimental observation was attributed to the formation of a coordination complex between $\mathrm{CuI}$ and $L$-carnitine that prevented the unwanted oxidation of $\mathrm{Cu}(\mathrm{I})$ into $\mathrm{Cu}(\mathrm{II})$. Lately, García-Alvarez and co-workers demonstrated that the use of the eutectic mixture formed by choline chloride and glycerol $(1 \mathrm{ChCl} / 2 \mathrm{Gly})$ allowed the use of milder reaction conditions (room temperature and $1 \mathrm{~mol} \%$ of $\mathrm{CuI}$ ) although longer reaction times $(14 \mathrm{~h})$ were needed to reach quantitative yields (97\%, Scheme 5c) [29]. At this point, it is important to note that, when the eutectic mixture $1 \mathrm{ChCl} / 2 \mathrm{Gly}$ was replaced by volatile and hazardous $\mathrm{CH}_{2} \mathrm{Cl}_{2}$, under the same catalytic conditions, a longer reaction time $(24 \mathrm{~h})$ was needed to achieve quantitative conversion.
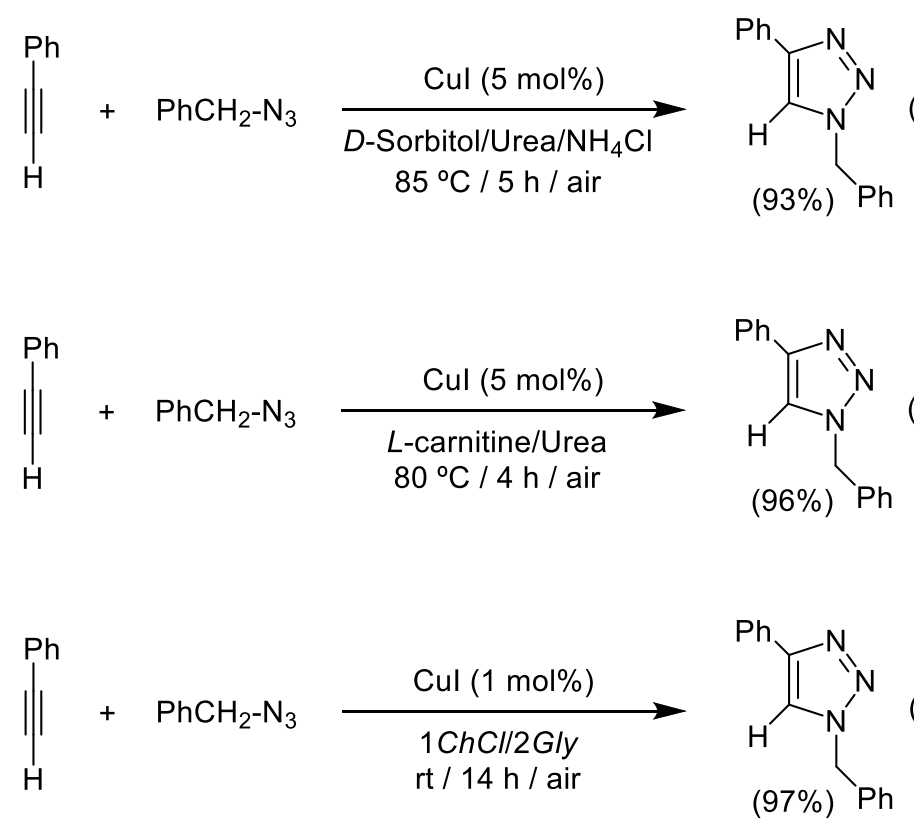

Scheme 5. CuI-catalyzed cycloaddition of azides and alkynes in the Deep Eutectic Mixtures (DESs): D-Sorbitol/Urea/ $\mathrm{NH}_{4} \mathrm{Cl}$ (a); L-carnitine/Urea (b); or Choline Chloride/Glycerol (c).

More recently, and bearing in mind the positive effect observed in CuAAC when: (i) the eutectic mixture $1 \mathrm{ChCl} / 2 \mathrm{Gly}$ was employed as sustainable solvent, and (ii) nitrogenated ligands (amines) are added as co-catalyst to the reaction media; Handy et al. reported the CuI-catalyzed cycloaddition of in-situ generated aryl azides with terminal alkynes by employing the aforementioned $1 \mathrm{ChCl} / 2 \mathrm{Gly}$ eutectic mixture as sustainable solvent in the presence of $N, N$-dimethylethylenediamine (DMEAD, 
$20 \mathrm{~mol} \%$ ) as co-catalyst. Although the catalytic system was recycled up to 4 consecutive cycles, quite drastic reaction conditions $\left(75^{\circ} \mathrm{C}, 10 \mathrm{~mol} \%\right.$ of $\mathrm{CuI}$ and $5-10 \mathrm{~h}$, see Scheme 6$)$ were still needed to achieve moderate to good yields (40-88\%) [54,55].

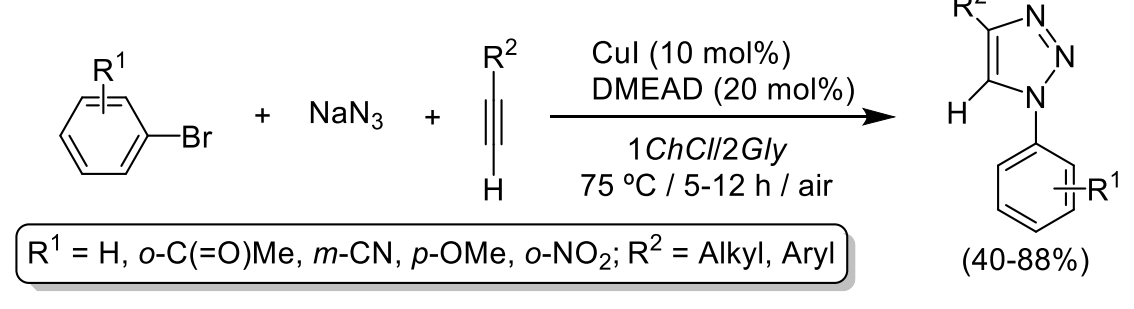

Scheme 6. CuI-catalyzed three-component cycloaddition of in-situ generated aryl azides and terminal alkynes in the eutectic mixture $1 \mathrm{ChCl} / 2 \mathrm{Gly}$.

\section{Cu-Catalyzed 1,3-Dipolar Cycloaddition of Azides and Alkynes (CuAAC) in Water}

In opposite to the more traditional VOCs, the use of water as a reaction media offers multiple advantages such as: (i) its non-toxicity and non-flammability; (ii) elevated boiling point; (iii) high availability and low price; and (iv) non-miscibility with organic compounds that enables easy product separation and catalyst recycling upon decantation. Taken together, and in agreement with the principles of green chemistry, water [19] emerges as one of the most attractive solvents in terms of sustainability and often represents the solvent of choice when dealing with CuAAC processes. This is in part due to the pioneering work reported by Sharpless and Fokin in 2002 occurring in aqueous solutions (2:1 mixture of water and $\left.{ }^{t} \mathrm{BuOH}\right)$ [9] that inspired a plethora of international research groups worldwide to study CuAAC reactions in this environmentally friendly solvent. On the other hand, and keeping in mind that the state of the art for the CuAAC processes has been reviewed recently [56-62], this section focuses on most representative examples appeared since 2015 merging the use of molecular copper catalysts and pure aqueous media.

In spite of the well documented viability of $\mathrm{CuAAC}$ reactions in pure water under ligandand additive-free conditions [63], the finding of highly efficient CuAAC procedures catalyzed by commercially available $\mathrm{Cu}$ salts is an active research area. In this sense, impressive substrate scope was reached recently by Jiang and $\mathrm{Xu}$ using $\mathrm{Cu}$ (II) catalysts in very low metallic charges (see Scheme 7a,b) [64,65]. Both $\mathrm{Cu}(\mathrm{II})$ catalysts $\left(\mathrm{CuSO}_{4} \cdot 5 \mathrm{H}_{2} \mathrm{O}\right.$ [64] or $\mathrm{Cu}(\mathrm{acac})_{2}$ [65]) required harsh conditions. In contrast, they proved efficient for the three-component synthesis of 1,4-disubstituted 1,2,3-triazoles starting from terminal alkynes, $\mathrm{NaN}_{3}$ and organic halides ( $\left.\mathrm{R}-\mathrm{X}\right)$.

Milder conditions were required using $\mathrm{CuCl}_{2}$ as catalyst in combination with an organic photosensitizer (eosin Y disodium salt (EY)) and green LED irradiation (Scheme 7c) [66]. The $\mathrm{CuCl} / \mathrm{EY}$ photocatalytic system enabled the isolation of a broad family of 1,4-disubstituted 1,2,3-triazoles in moderate to excellent yields (49-100\%) and the aforementioned catalytic system was recycled up to three consecutive runs [66].

An additional example of ligand-free $\mathrm{CuAAC}$ protocols in neat water includes the use of ultrasound irradiation [67] to enhance the activity of a $\mathrm{Cu}(\mathrm{I})$ salt (i.e., $\mathrm{CuCl}$ ) as catalyst (Scheme 8). In this sense, Chen, $\mathrm{Qu}$ and co-workers used $\mathrm{CuCl}$ (10 mol\%) to build 1,4-disubstituted 1,2,3-triazoles at room temperature upon ultrasound irradiation $(150 \mathrm{~W})$, including a family of triazoles generated from coumarine-derived alkynes or azides thereby granting access to highly functionalized heterocycles that were isolated in ca. 90\% yield (see Scheme 8a,b) [67]. Remarkably, lower yields were reached in the absence of ultrasonic power, even in the presence of trimethylamine as co-catalyst, or when using mixtures $\mathrm{H}_{2} \mathrm{O} /$ VOCs or pure organic solvents (DMSO, DMF, toluene or ${ }^{t} \mathrm{BuOH}$ ) instead of neat water as a reaction medium. 

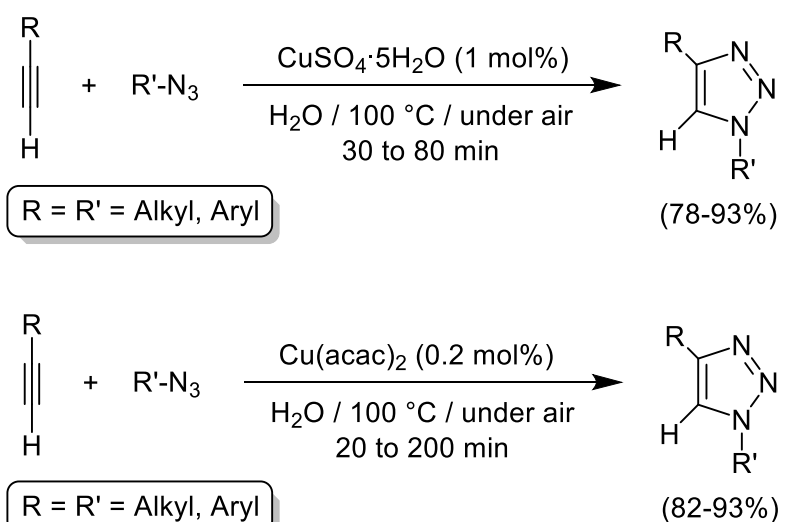

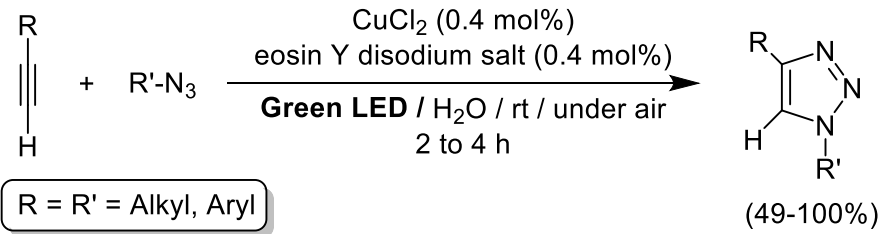

Scheme 7. Ligand-free $\mathrm{Cu}(\mathrm{II})$-catalyzed 1,3-dipolar cycloaddition of azides and alkynes (CuAAC) in pure water enabled by thermal treatment (equations $(\mathbf{a}, \mathbf{b})$ ) or green LED irradiation (equation (c)).

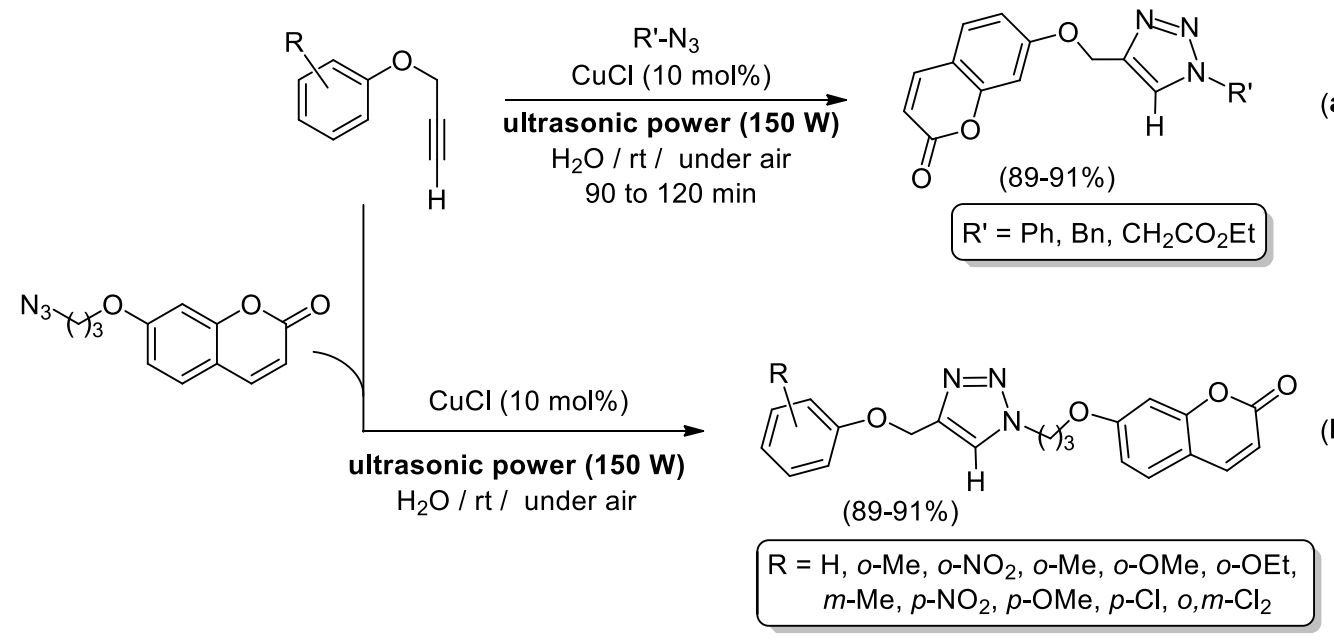

Scheme 8. Ligand-free CuCl-catalyzed 1,3-dipolar cycloaddition of terminal alkynes (CuAAC) with common organic azides (a) or coumarine-derived azides $(\mathbf{b})$ in water.

The efficiency of the CuAAC reactions in aqueous media can be improved using heteroatom-based donor ligands that enhance the solubility and stability of the $\mathrm{Cu}$ catalyst. Classical examples of this strategy combined $\mathrm{CuX}$ species $(\mathrm{X}=\mathrm{I}, \mathrm{Br})$ and $\mathrm{NEt}_{3}$ [68], $\mathrm{N}$-alkylimidazoles [69] or thioethers [70,71]. In 2014, Sarma and colleagues carried out the cycloaddition of organic azides with terminal alkynes in excellent yields (82-92\%) catalyzed by CuI (0.5 mol\%) and the hydroquinidine-1,4-phthalazinediyl ligand ((DHQD) $)_{2} \mathrm{PHAL} ; 1 \mathrm{~mol} \%$ ) in pure water (see Scheme 9a) [72]. The efficiency of the CuI/ (DHQD) $)_{2}$ PHAL catalytic system in the 1,3-dipolar cycloaddition of phenylacetylene and benzyl azide was completely inhibited in absence of ligand, and the beneficial effect of water was demonstrated by the lower activity of the aforementioned catalytic system when using volatile organic solvents such as THF, $\mathrm{CH}_{2} \mathrm{Cl}_{2}$, DMSO, DMF, acetone, toluene, or mixtures $\mathrm{H}_{2} \mathrm{O} /{ }^{t} \mathrm{BuOH}$ [72]. $\mathrm{Cu}(\mathrm{OAc})_{2}$ and hydrazine monohydrate $\left(\mathrm{NH}_{2} \mathrm{NH}_{2} \cdot \mathrm{H}_{2} \mathrm{O}\right)$ was used by $\mathrm{Xu}$ and co-workers to prepare a family of 1,4-disubstituted 1,2,3-triazoles in neat water (see Scheme 9b) [73]. In this case, the hydrazine behaves 
as stoichiometric reducing agent to generate $\mathrm{Cu}(\mathrm{OAc})$ species in-situ that underwent spontaneous decomposition in aqueous media to produce spherical $\mathrm{Cu}_{2} \mathrm{O}-\mathrm{NPs}$ with size distribution ranging from 400 to $500 \mathrm{~nm}$ (characterized by powder XRD, SEM and TEM). It should be noted that the excellent catalytic activity and robustness of discrete $\mathrm{Cu}_{2} \mathrm{O}$ species in AAC reactions occurring in neat water at room temperature and in absence of additives was noticed back in 2011 by Bi and Zhang [63], also pointing to the key role of water since only traces (DMSO, THF, and $\mathrm{MeOH}$ ) or very low conversions $\left(<20 \% ; \mathrm{CHCl}_{3}\right)$ were reached using volatile organic solvents. Interestingly, the $\mathrm{Cu}(\mathrm{OAc})_{2}$ to $\mathrm{Cu}_{2} \mathrm{O}-\mathrm{NPs}$ conversion co-produced HOAc as by-product, that suggested the beneficial role of acidic media for the CuAAC reaction to proceed [73]. Built on these observations, the same group developed the fast and high-yielding 1,3-dipolar cycloaddition of organic azides with terminal alkynes catalyzed by $\mathrm{Cu}_{2} \mathrm{O}(0.5 \mathrm{~mol} \%)$ in neat water using carboxymethylpullulans (CMP; $5 \mathrm{~mol} \%$ ) as a mild source of protons (see Scheme 9c) [74]. Remarkably, the $\mathrm{Cu}_{2} \mathrm{O} / \mathrm{CMP}$ catalytic system was efficiently recycled up to 6 consecutives runs, and might be recycled six additional runs upon acidic treatment that reactivates the CMP co-catalyst. Joint work performed by the groups of Pericàs and Gómez proved the pivotal role of long chain alkyl amines in CuAAC reactions taking place in polar solvents such as alcohols, dioxane and pure water [34]. For the case of water, the authors clearly illustrated the need of $\mathrm{HN}(\text { octyl })_{2}$ or oleylamine in catalytic amounts to reach nearly quantitative yield of 1-benzyl-4-phenyl-1H-1,2,3-triazole, whereas negligible amounts of the cycloaddition product where isolated in presence of $\mathrm{NEt}_{3}(5 \mathrm{~mol} \%)$ or in the absence of any additive (13\%; see Scheme $\left.9 \mathrm{~d}\right)$ [34].
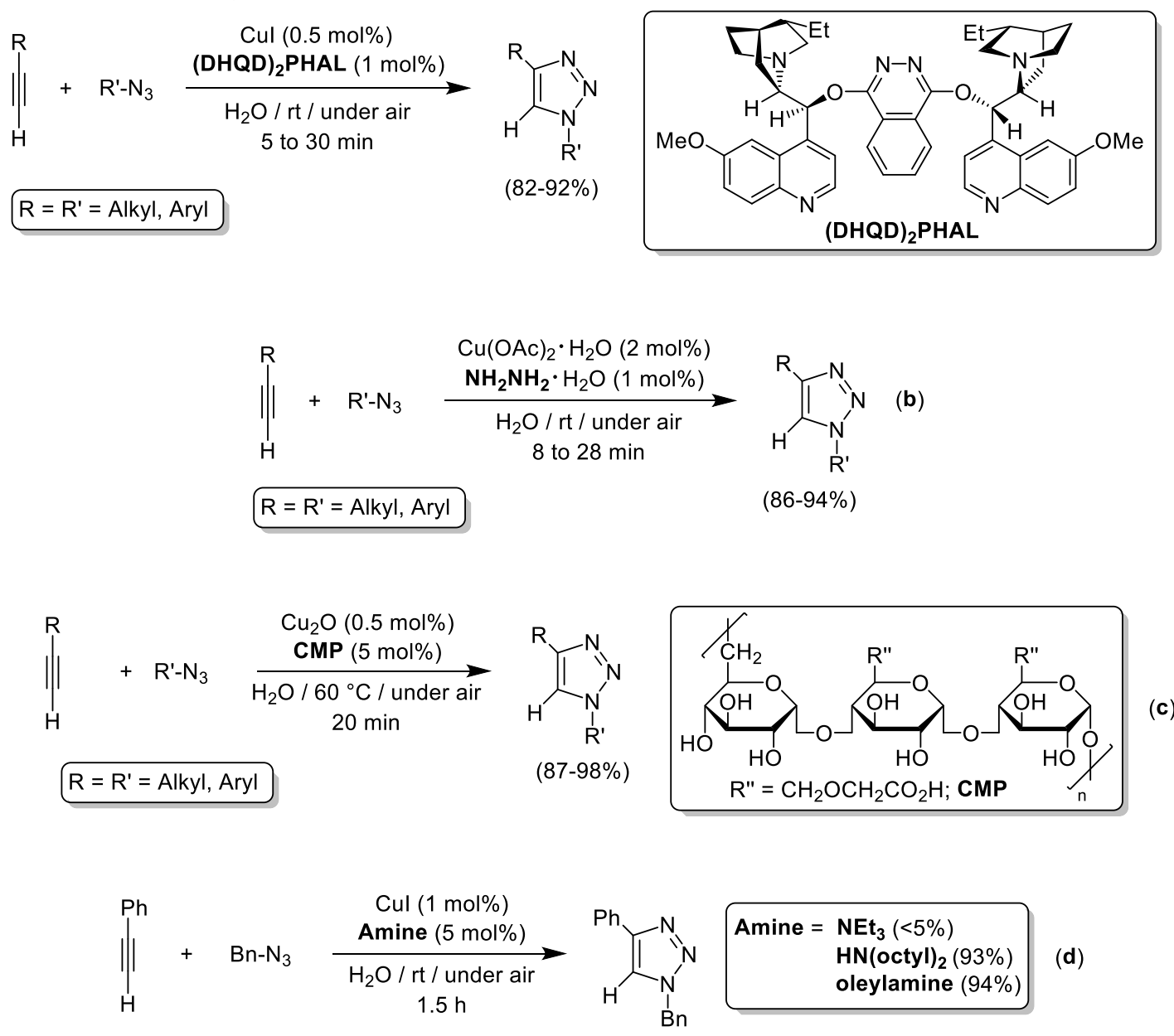

Scheme 9. CuAAC reactions in pure water enabled by commercially available $\mathrm{Cu}$-salts and nitrogen compounds $(\mathbf{a}, \mathbf{b}, \mathbf{d})$ or proton sources $(\mathrm{CMP} ;(\mathbf{c}))$. 
Copper acetylides are commonly invoked as catalytic intermediates in CuAAC reactions, which makes the synthesis of functionalized 1,2,3-triazoles from internal alkynes typically unreachable. This limitation is frequently circumvented using internal iodoalkynes [75], thus allowing for further modification of the triazole skeleton. An elegant approach to 5-iodo-1,2,3-triazoles taking place in water via three-component reaction between terminal alkynes, organic azides and $\mathrm{NaI}$ was discovered recently by Li, Cui and Zhang (see Scheme 10) [76]. After careful optimization of the reaction conditions (10 mol\% of $\mathrm{CuI}$ along with equimolar amounts of NaI, DIPEA (diisopropylethylamine), TBACl (tetrabutylammonium chloride), Selectfluor (1.2 equiv of each), and mild heating), the authors isolated a number of 5-iodo-1,2,3-triazoles in yields ranging from 72 to $91 \%$. By applying this catalytic cocktail, broad substrate scope and functional group tolerance was reached, including the incorporation of relevant motifs such as sugars, fluorophore groups, or peptides.
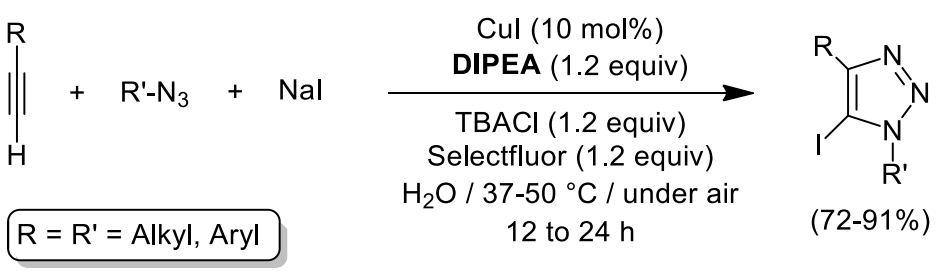

Scheme 10. Synthesis of 5-iodo-1,2,3-triazoles mediated by CuI, DIPEA and TBACl in pure water upon oxidizing conditions.

The use of well-defined $\mathrm{Cu}$ complexes as catalysts for the $\mathrm{CuAACs}$ in aqueous media has been extensively studied using phosphorus-donor ligands [77,78], N-Heterocyclic Carbenes (NHC) [79-81], or PTA-derived iminophosphoranes (PTA $=1,3,5$-Triaza-7-phosphaadamantane) [82,83]. To the best of our knowledge, the first isolated and fully characterized copper species bearing an $\mathrm{N}$-donor ligand that proved efficient in CuAAC reactions using pure water as solvent was reported by Pericàs back in 2009 using a 1:1 complex of $\mathrm{CuCl}$ and the tris(1-benzyl-1H-1,2,3-triazol-4-yl)methanol ligand [84]. Pursuing this approach, Pericàs and co-workers prepared a family of $\mathrm{Cu}$-complexes (1a-f) bearing tris(triazolyl)methane ligands that catalyzed the cycloaddition of benzyl azide with phenylacetylene at room temperature in neat water as a solvent (see Scheme 11a) [85]. A comparative study using the simplest and hydrophilic $\mathrm{Cu}$ species $\mathbf{1 b}\left(\mathrm{R}=\mathrm{H} ; \mathrm{R}^{\prime}=\mathrm{Ph}\right)$, which behaved as the most efficient catalyst for the model reaction between phenylacetylene and benzyl azide, has revealed the positive impact of water (vs. hexanes, toluene, $\mathrm{CH}_{2} \mathrm{Cl}_{2}, \mathrm{THF}$ or $\mathrm{CH}_{3} \mathrm{CN}$ ) on the catalytic activity of $\mathbf{1 b}$ [85]. The (2-pyrrolecarbaldiminato)-Cu(II) catalyst 2 allowed the three-component and high-yielding synthesis of 1,4-disubstituted 1,2,3-triazoles (see Scheme 11b) [86]. Interestingly, the scope is restricted to the use of benzyl halides which leaves the inert aryl-Cl and/or aryl-Br bonds intact for further functionalization [86]. The groups of Mahmudov and Pombeiro carried out the three-component coupling of phenylacetylene, benzyl bromide and $\mathrm{NaN}_{3}$ in neat water catalyzed by the $\mathrm{Cu}$ (II)-catalyst $3 \cdot 2 \mathrm{H}_{2} \mathrm{O}(3 \mathrm{~mol} \%)$ upon microwave irradiation $(10 \mathrm{~W})$ and strong heating $\left(125^{\circ} \mathrm{C}\right.$; see Scheme 11c) [87]. Nevertheless, the harsh conditions only permitted the isolation of the model 1-benzyl-4-phenyl-1H-1,2,3-triazole in 74\% yield. A last example of AAC enabled by well-defined [(NHC) $\mathrm{CuCl}$ species 4 was given by the group of Szadkowska [88]. In order to enhance the solubility of 4 in aqueous media, the authors used a hydrophilic NHC ligand containing the theophylline backbone and an ammonium moiety. This ligand design strategy proved right and was key to enhance the catalytic activity of 4 in neat water that surpassed the one found in non-polar organic solvents (toluene or ethers), alcohols (glycerol or $\mathrm{MeOH}$ ), $\mathrm{CH}_{2} \mathrm{Cl}_{2}, \mathrm{DMSO}$ or mixtures $\mathrm{H}_{2} \mathrm{O} /{ }^{t} \mathrm{BuOH}$. In addition, the three-component synthesis of functionalized triazoles was accomplished using low copper loadings ( $1 \mathrm{~mol} \%$ of 4 ) and mild conditions (room temperature; see Scheme 11d) [88]. 

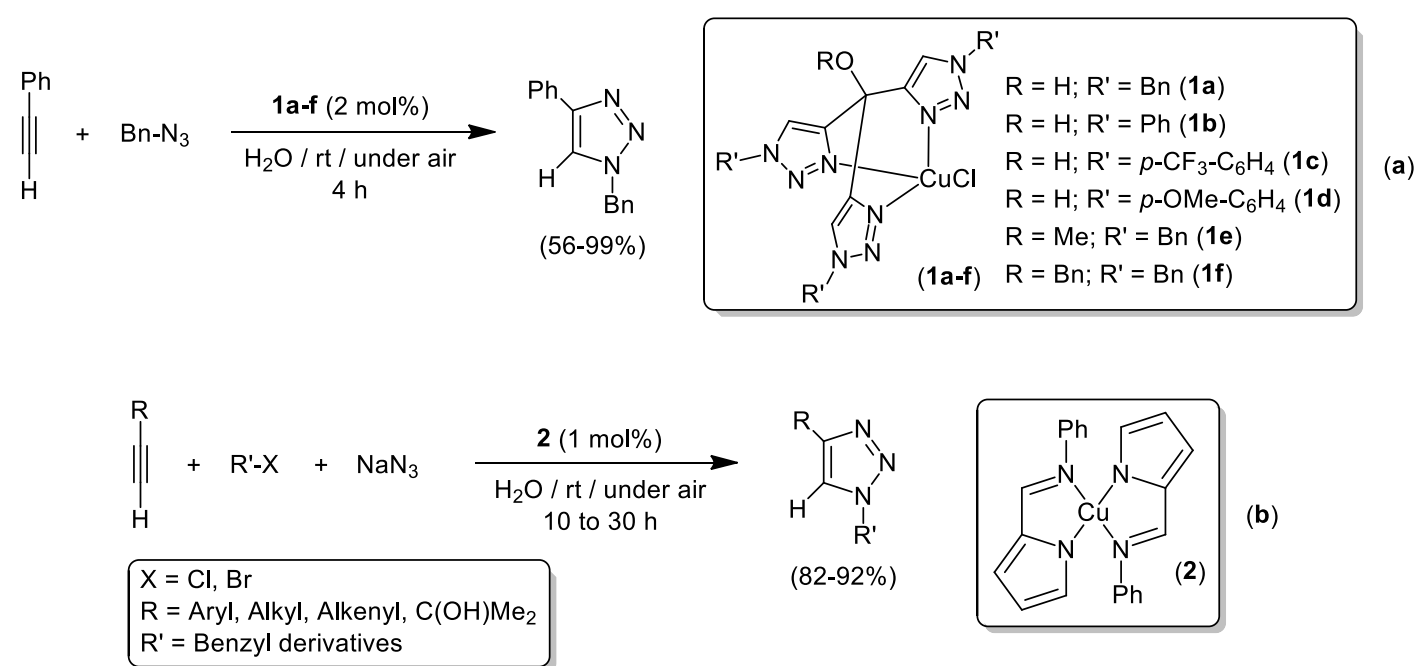

$(82-92 \%)$

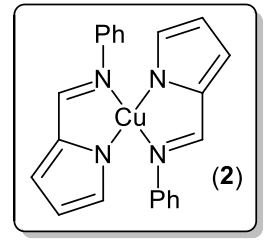

(b)

||$_{\mathrm{H}}^{\mathrm{Ph}}+\mathrm{Bn}-\mathrm{Br}+\mathrm{NaN}_{3}$

$\left.\right|_{\mathrm{H}} ^{\mathrm{R}}+\mathrm{R}^{\prime} \widehat{\mathrm{X}}+\mathrm{NaN}_{3}$

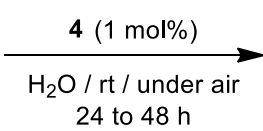

$\mathrm{X}=\mathrm{Cl}, \mathrm{Br}$

$\mathrm{R}=$ Aryl, Alkyl; R' = Aryl

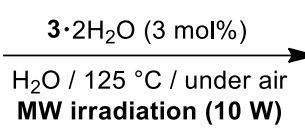
$15 \mathrm{~min}$<smiles>Brc1cccc(-c2ccccc2)c1</smiles>

$(74 \%)$

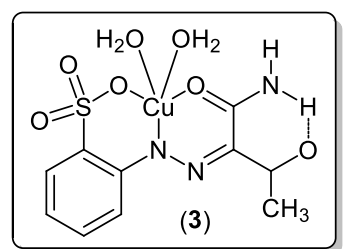

(c)

Scheme 11. CuAAC reactions in neat water catalyzed by $\mathrm{Cu}$-complexes containing tris(triazolyl)methane (a), 2-pyrrolecarbaldiminato (b), arylhydrazone (c) or hydrophilic NHC (d) ligands.

In 2014, Astruc and colleagues performed the 1,3-dipolar cycloaddition of terminal alkynes and organic azides enabled by either [Cu(hexabenzyltren) $\mathrm{Br}]$ (tren = triaminoethylamine; complex 5 in Scheme 12) or the Sharpless-Fokin catalyst $\left[\mathrm{CuSO}_{4} \cdot 5 \mathrm{H}_{2} \mathrm{O}\right.$ and sodium ascorbate (NaAsc) in Scheme 12] using micellar catalysis at nearly room temperature [89]. To meet success, the amphiphilic dendrimer 6 that bears 27 triethylene glycol (TEG) units and nine intradentritic triazoles was used in catalytic amounts allowing the encapsulation of the $\mathrm{Cu}(\mathrm{I})$ active sites (Scheme 12) [89]. The resulting $\mathrm{Cu}(\mathrm{I})$-containing nanoreactor permitted the isolation of several 1,4-disubstituted 1,2,3-triazoles in excellent yields and with excellent TON values (up to 510000). Moreover, at this point it is important to note that the authors reported the recycling (up to 10 consecutive runs) of the amphiphilic dendrimer 6 using the $\mathrm{Cu}(\mathrm{I})$-catalyst 5 .

A year later, a similar approach was employed by Shin and Lim to isolate a family of glycidyl triazolyl polymers via CuAACs using $\mathrm{CuSO}_{4} \cdot 5 \mathrm{H}_{2} \mathrm{O}(5 \mathrm{~mol} \%)$, sodium ascorbate (NaAsc, $15 \mathrm{~mol} \%$ ) and $\beta$-cyclodextrin $(\beta-C D ; 2.5 \mathrm{~mol} \%)$ using neat water as solvent (see Scheme 13) [90]. The replacement of $\beta-C D$ by the zwitterionic surfactant Betaine permitted the groups of Lee and Lim to achieve the quantitative cycloaddition of phenylacetylene and benzyl azide combining $\mathrm{CuSO}_{4} \cdot 5 \mathrm{H}_{2} \mathrm{O}(25 \mathrm{ppb})$, sodium ascorbate (15 mol\%) and Betaine (5 mol\%; see Scheme 14) [91]. Upon these conditions, very impressive TON and TOF values $\left(32,000,000\right.$ and $1,333,333 \mathrm{~h}^{-1}$, respectively) were accomplished at nearly room temperature, and the micellar aqueous medium was reused up to three cycles [although higher copper charges (200 ppm) and longer reaction times were required to reach completion]. 
In addition, the catalytic system was applied to the isolation of 1-benzyl-4-phenyl-1H-1,2,3-triazole in a gram scale using 2.5 ppm of Cu-catalyst (95\% yield), and the scope of the reaction was extended to a family of aryl, alkyl, and ferrocenyl acetylenes, furnishing the corresponding triazoles in 76-98\% yield upon very mild conditions (copper loadings of 25-200 ppm and heating at $30^{\circ} \mathrm{C}$ ).

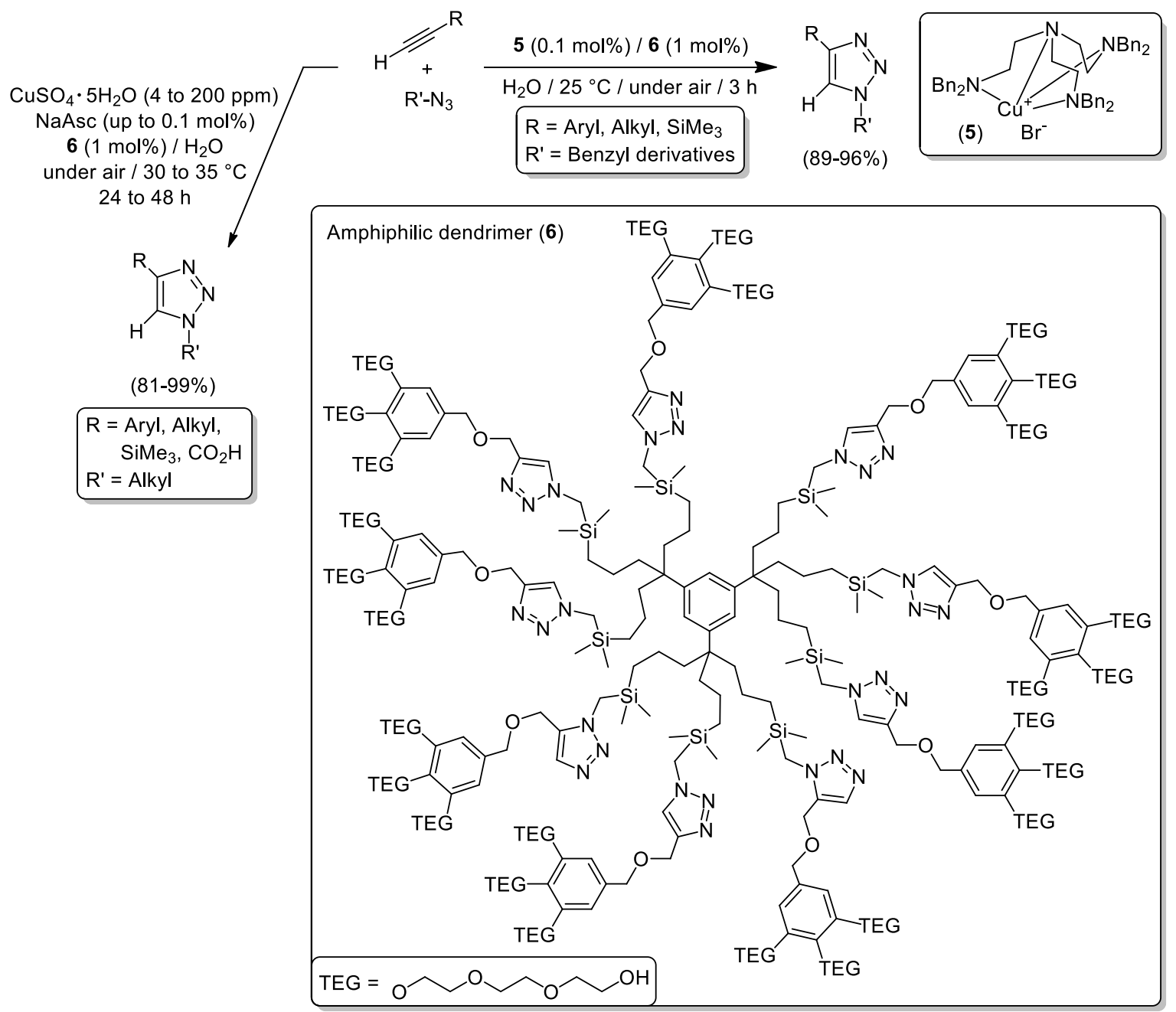

Scheme 12. CuAAC using [Cu(hexabenzyltren)Br] (5) or $\mathrm{CuSO}_{4} /$ sodium ascorbate (NaAsc) catalytic systems and enabled by the amphiphilic dendrimer (6).

Last but not least, the group of Scarso proved that micellar catalysis can be applied to the CuAAC reaction in its three-component version. Thus, the selective coupling of terminal alkynes, organic bromides and $\mathrm{NaN}_{3}$ efficiently proceeds using the lipophilic catalyst $[\mathrm{Cu}(\mathrm{IMes}) \mathrm{Cl}]$ (1 mol\% Cu; IMes = 1,3-bis(2,4,6-trimethylphenyl)imidazol-2-ylidene) ) and the commercially available surfactants named sodium lauryl sulfosuccinate (SLS) or $D L$ - $\alpha$-tocopherol methoxypolyethylene glycol succinate (TPGS-750-M) giving access to the corresponding triazoles in variable yields (51-98\%; see Scheme 15) [92]. It is important to note that the efficiency of [ $\mathrm{Cu}(\mathrm{IMes}) \mathrm{Cl}]$ upon micellar conditions to achieve the 1,3-dipolar cycloaddition between 1-octyne and benzyl azide notably outperforms its catalytic activity using volatile organic solvents such as $\mathrm{CH}_{2} \mathrm{Cl}_{2}$ or $\mathrm{MeOH}$, that only produced the desired triazole in ca. 5\%. Unfortunately, attempts to make possible the recycling of the micellar catalytic system proved unfruitful and the model triazole was isolated in only $27 \%$ yield. 

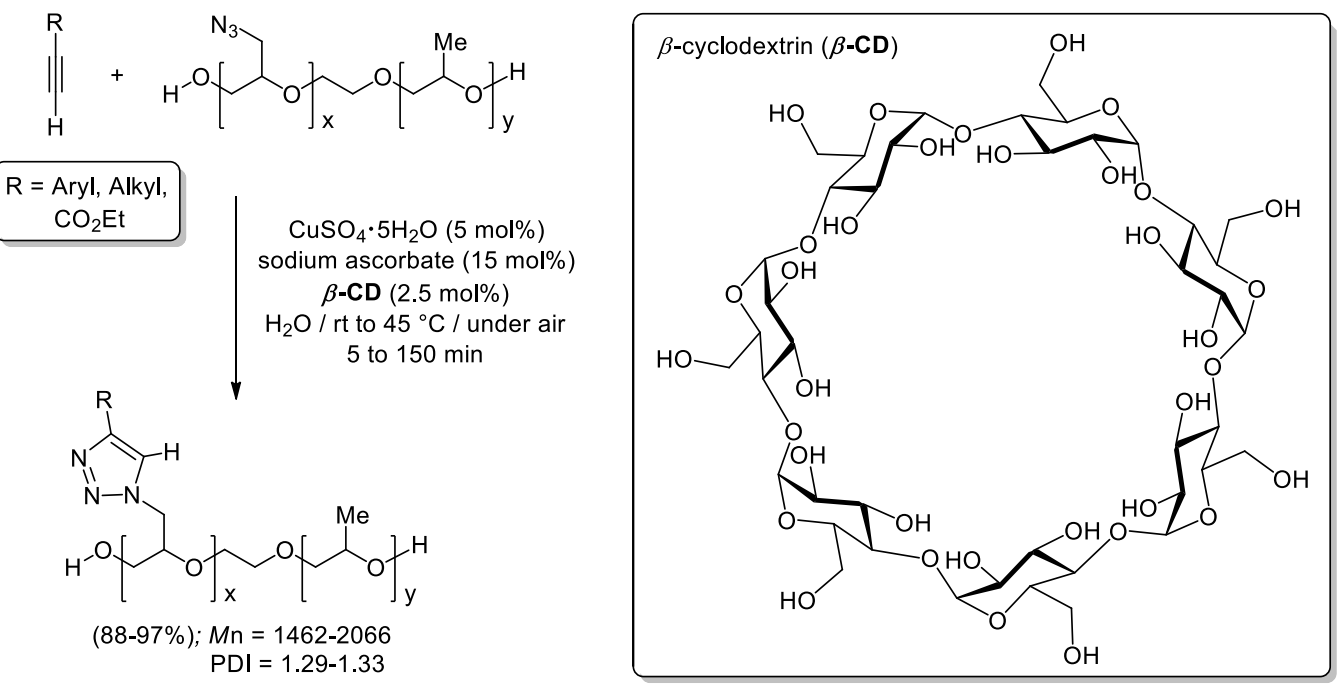

Scheme 13. CuAAC in micellar medium using the Sharpless-Fokin catalyst and $\beta$-cyclodextrin $(\beta-C D)$.<smiles>[C+]#C[Pb]</smiles>

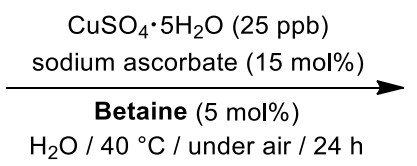<smiles>[B]c1nn[nH]c1P</smiles><smiles>C[N+](C)(C)CC(=O)[O-]</smiles>
$(100 \%)$

Scheme 14. CuAAC mediated by the Sharpless-Fokin catalyst and Betaine in pure water.
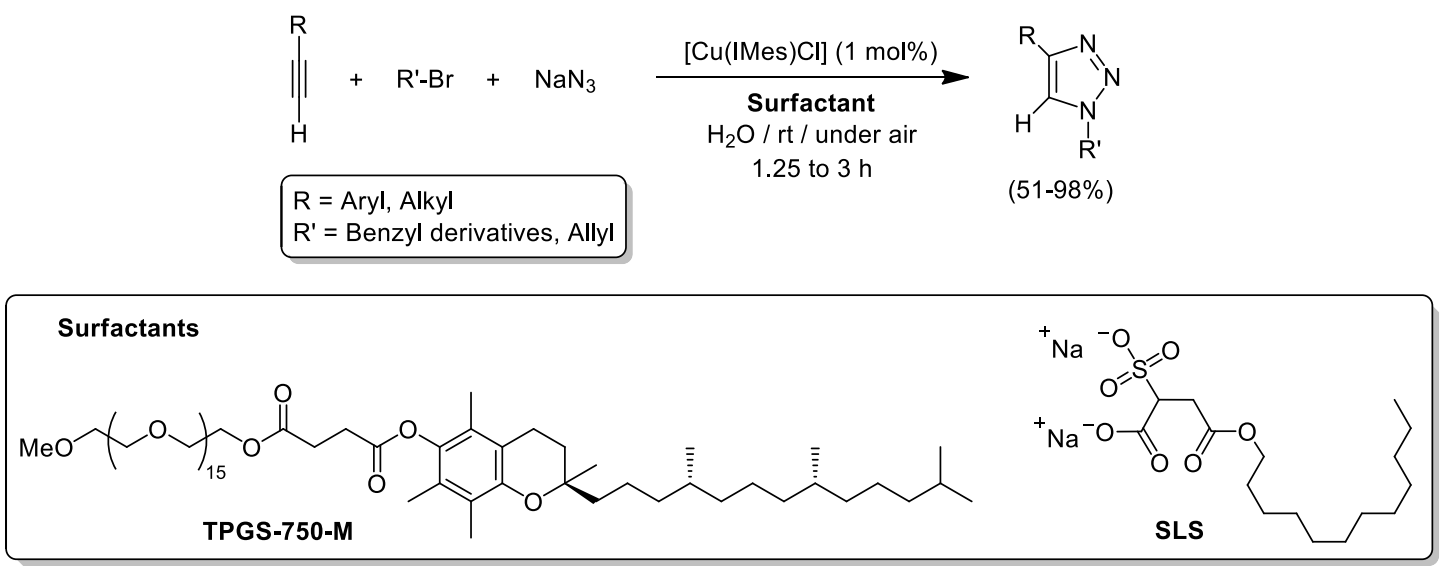

Scheme 15. Three-component synthesis of 1,4-disubstitued 1,2,3-triazoles mediated by [Cu(IMes)Cl] and commercially available surfactants (TPGS-750-M or SLS) in aqueous media.

\section{Conclusions}

"Click" criteria has been designed in order to reduce chemical waste production and favor the easy manipulation and isolation of the targeted high-value commodities. Amongst all metal-catalyzed transformations coming into existence upon strict "click" criteria, the copper-catalyzed azide-alkyne cycloaddition (CuAAC) occupies a preferential place, and represents one of the most reliable synthetic tools in organic chemistry, leading to functionalized triazoles in a one-pot manner. This mini review collects remarkable contributions to the CuAAC reaction obeying the "click" criteria and occurring in environmentally friendly solvents namely: glycerol (Gly), Polyethylene glycol (PEG), Deep Eutectic mixtures (DESs) or water. As a general trend, CuAAC reactions can be achieved 
using either commercially available $\mathrm{Cu}$-salts or in-house made $\mathrm{Cu}$ complexes containing an ancillary ligand, usually under mild reaction conditions. Although less common, different ways to enhance the catalytic activity of simple $\mathrm{CuX}$ and $\mathrm{CuX}_{2}$ salts in AACs include: (i) the combination of an organic photosensitizer and green LED irradiation; (ii) the controlled protonation of the $\mathrm{Cu}_{2} \mathrm{O}$-catalyst using mild proton sources; (iii) the design of micellar aqueous solutions; and (iv) the use of sonication power or MW irradiation. By using these approaches, more efficient procedures were developed allowing to: (i) decrease the catalyst loadings up to ppb levels providing excellent TON and TOF values $(32,000,000$ and 1,333,333 $\mathrm{h}^{-1}$, respectively); (ii) improve the substrate scope; and (iii) achieve the recovery of the $\mathrm{Cu}$-catalyst and perform recycling experiments. In spite of growing interest in the field of CuAAC reactions using novel environmentally-friendly solvents, considerable room is still available for the improvement of this technology using the emerging "green solvents" named glycerol (Gly) and deep eutectic mixtures (DESs) as only a handful of examples have been reported in the literature.

Funding: J.G.-Á. thanks: PhosAgro/UNESCO/IUPAC for the award of a Green Chemistry for Life Grant; and Spanish MINECO (Projects CTQ2016-81797-REDC and CTQ2016-75986-P).

Acknowledgments: N.N. acknowledges the CNRS and UPS for continuous support and the Institut de Chimie de Toulouse for the attribution of the ICT Young Investigator Award 2020.

Conflicts of Interest: The authors declare no conflict of interest.

\section{References}

1. Anilkumar, G.; Saranya, S. (Eds.) Copper Catalysis in Organic Chemistry; Wiley-VCH Verlag GmbH \& Co. KGaA: Weinheim, Germany, 2020.

2. Alexakis, A.; Krause, N.; Woodward, S. (Eds.) Copper Catalyzed Asymmetric Synthesis; Wiley-VCH Verlag GmbH \& Co. KgaA: Weinheim, Germany, 2014.

3. Evano, G.; Blanchard, N. (Eds.) Copper-Mediated Cross-Coupling Reactions; John Wiley \& Sons Ltd.: Hoboken, NJ, USA, 2014.

4. Lipshutz, B.; Yoshinori, Y. Introduction: Coinage Metals in Organic Synthesis. Chem. Rev. 2008, 108, $2793-2795$. [CrossRef]

5. Festa, R.A.; Thiele, D.J. Copper: An Essential Metal in Biology. Curr. Biol. 2011, 21, R877-R883. [CrossRef]

6. Gawande, M.B.; Goswami, A.; Felpin, F.-X.; Asefa, T.; Huang, X.; Silva, R.; Zou, X.; Zboril, R.; Varma, R.S. $\mathrm{Cu}$ and $\mathrm{Cu}$-Based Nanoparticles: Synthesis and Applications in Catalysis. Chem. Rev. 2016, 116, 3722-3811. [CrossRef] [PubMed]

7. Kolb, H.C.; Finn, M.G.; Sharpless, K.B. Click Chemistry: Diverse Chemical Function from a Few Good Reactions. Angew. Chem. Int. Ed. 2001, 40, 2004-2021. [CrossRef]

8. Tornøe, C.W.; Christensen, C.; Meldal, M. Peptidotriazoles on Solid Phase: [1,2,3]-Triazoles by Regiospecific Copper(I)-Catalyzed 1,3-Dipolar Cycloadditions of Terminal Alkynes to Azides. J. Org. Chem. 2002, 67, 3057-3064. [CrossRef] [PubMed]

9. Rostovtsev, V.V.; Green, L.G.; Fokin, V.V.; Sharpless, K.B. A Stepwise Huisgen Cycloaddition Process: Copper(I)-Catalyzed Regioselective "Ligation" of Azides and Terminal Alkynes. Angew. Chem. Int. Ed. 2002, 41, 2596-2599. [CrossRef]

10. Huisgen, R.; Pawda, A. (Eds.) 1,3-Dipolar Cycloaddition Chemistry; John Wiley \& Sons, Ltd.: New York, NY, USA, 1984; Volume 1.

11. Baskin, J.M.; Bertozzi, C.R. Copper-free Click Chemistry: Bioorthogonal Reagents for Tagging Azides. Aldrichim. Acta 2010, 43, 15-23.

12. McNulty, J.; Keskar, K.; Vemula, R. The First Well-Defined Silver(I)-Complex-Catalyzed Cycloaddition of Azides onto Terminal Alkynes at Room Temperature. Chem. Eur. J. 2011, 17, 14727-14730. [CrossRef]

13. Zhang, L.; Chen, X.; Xue, P.; Sun, H.H.Y.; Williams, I.D.; Sharpless, K.B.; Fokin, V.V.; Jia, G. Ruthenium-Catalyzed Cycloaddition of Alkynes and Organic Azides. J. Am. Chem. Soc. 2005, 127, 15998-15999. [CrossRef]

14. Ding, S.; Jia, G.; Sun, J. Iridium-catalyzed intermolecular azide-alkyne cycloaddition of internal thioalkynes under mild conditions. Angew. Chem. Int. Ed. 2014, 53, 1877-1880. [CrossRef] 
15. Rao, H.S.P.; Chakibanda, G. Raney Ni catalyzed azide-alkyne cycloaddition reaction. RSC Adv. 2014, 4, 46040-46048. [CrossRef]

16. Chandrasekaran, S. (Ed.) Click Reactions in Organic Synthesis; Wiley-VCH Verlag GmbH \& Co. KGaA: Weinheim, Germany, 2016.

17. Reichardt, C.; Welton, T. Solvents and Solvent Effects in Organic Chemistry, 4th ed.; Wiley-VCH: Weinheim, Germany, 2010.

18. Scott, J.L.; Sneddon, H.F. Green Solvents. In Green Techniques for Organic Synthesis and Medicinal Chemistry; Zhang, W., Cue, B.W., Eds.; John Wiley \& Sons: Hoboken, NJ, USA, 2018.

19. Anastas, P.T. Handbook of Green Chemistry, Volume 5: Reactions in Water; Li, C.-J., Ed.; Wiley-VCH: Weinheim, Germany, 2010.

20. Ravichandiran, P.; Gu, Y. Glycerol as Eco-Efficient Solvent for Organic Transformations, in Bio-Based Solvents; Jérôme, F., Luque, R., Eds.; John Wiley \& Sons: Hoboken, NJ, USA, 2017.

21. Vaccaro, L.; Santoro, S.; Curini, M.; Lanari, D. The emerging use of $\gamma$-valerolactone as a green solvent. Chem. Today 2017, 35, 46-48.

22. Pace, V.; Hoyos, P.; Castoldi, L.; Domínguez de María, P.; Alcántara, A.R. 2-Methyltetrahydrofuran (2-MeTHF): A Biomass-Derived Solvent with Broad Application in Organic Chemistry. ChemSusChem 2012, 5, 1369-1379. [CrossRef] [PubMed]

23. Yang, J.; Tan, J.-N.; Gu, Y. Lactic acid as an invaluable bio-based solvent for organic reactions. Green Chem. 2012, 14, 3304-3317. [CrossRef]

24. García-Álvarez, J. Deep Eutectic Solvents and Their Applications as New Green and Biorenewable Reaction Media. In Handbook of Solvents, Volume 2: Use, Health, and Environment, 3rd ed.; Wypych, G., Ed.; ChemTec Publishing: Toronto, ON, Canada, 2019.

25. Horváth, I.T. Solvents from nature. Green Chem. 2008, 10, 1024-1028. [CrossRef]

26. Rahmat, N.; Abdullah, A.Z.; Mohamed, A.R. Recent progress on innovative and potential technologies for glycerol transformation into fuel additives: A critical review. Renew. Sustain. Energy Rev. 2010, 14, 987-1000. [CrossRef]

27. Dapsens, P.Y.; Mondelli, C.; Pérez-Ramírez, J. Biobased Chemicals from Conception toward Industrial Reality: Lessons Learned and To Be Learned. ACS Catal. 2012, 2, 1487-1499. [CrossRef]

28. Gu, Y.; Jérôme, F. Glycerol as a sustainable solvent for green chemistry. Green Chem. 2010, 12, 1127-1138. [CrossRef]

29. Vidal, C.; García-Álvarez, J. Glycerol: A biorenewable solvent for base-free Cu(I)-catalyzed 1,3-dipolar cycloaddition of azides with terminal and 1-iodoalkynes. Highly efficient transformations and catalyst recycling. Green Chem. 2014, 16, 3515-3521. [CrossRef]

30. Trujillo, M.; Hull-Crew, C.; Outlaw, A.; Stewart, K.; Taylor, L.; George, L.; Duensing, A.; Tracey, B.; Schoffstall, A. Green Methodologies for Copper(I)-Catalyzed Azide-Alkyne Cycloadditions: A Comparative Study. Molecules 2019, 24, 973. [CrossRef]

31. Pasupuleti, B.G.; Bez, G. CuI/L-proline catalyzed click reaction in glycerol for the synthesis of 1,2,3-triazoles. Tetrahedron Lett. 2019, 60, 142-146. [CrossRef]

32. Rodríguez-Rodríguez, M.; Gras, E.; Pericàs, M.A.; Gómez, M. Metal-Free Intermolecular Azide-Alkyne Cycloaddition Promoted by Glycerol. Chem. Eur. J. 2015, 21, 18706-18710. [CrossRef] [PubMed]

33. Nandre, K.P.; Salunke, J.K.; Nandre, J.P.; Patil, V.S.; Borse, A.U.; Bhosale, S.V. Glycerol mediated synthesis of 5-substituted $1 H$-tetrazole under catalyst free condition. Chin. Chem. Lett. 2012, 23, 161-164. [CrossRef]

34. Rodríguez-Rodríguez, M.; Llanes, P.; Pradel, C.; Pericàs, M.A.; Gómez, M. Key non-metal ingredients for Cu-catalyzed" "Click" reactions in glycerol: Nanoparticles as efficient forwarders. Chem. Eur. J. 2016, 22, 18247-18253. [CrossRef] [PubMed]

35. Dang-Bao, T.; Pradel, C.; Favier, I.; Gómez, M. Bimetallic Nanocatalysts in Glycerol for Applications in Controlled Synthesis. A Structure-Reactivity Relationship Study. ACS Appl. Nano Mater. 2019, 2, 1033-1044. [CrossRef]

36. Sreedhar, B.; Reddy, P.S.; Kumar, N.S. Cu(I)-catalyzed one-pot synthesis of 1,4-disubstituted 1,2,3-triazoles via nucleophilic displacement and 1,3-dipolar cycloaddition. Tetrahedron Lett. 2006, 47, 3055-3058. [CrossRef]

37. Kumaraswamy, G.; Ankamma, K.; Pichaiah, A. Tandem Epoxide or Aziridine Ring Opening by Azide/Copper Catalyzed [3+2] Cycloaddition: Efficient Synthesis of 1,2,3-Triazolo $\beta$-Hydroxy or $\beta$-Tosylamino Functionality Motif. J. Org. Chem. 2007, 72, 9822-9825. [CrossRef] 
38. Damodiran, M.; Muralidharan, D.; Perumal, P.T. Regioselective synthesis and biological evaluation of bis(indolyl)methane derivatized 1,4-disubstituted 1,2,3-bistriazoles as anti-infective agents. Bioorg. Med. Chem. Lett. 2009, 19, 3611-3614. [CrossRef]

39. Kumar, D.P.; Reddy, V.B. An Efficient, One-Pot, Regioselective Synthesis of 1,4-Diaryl-1H-1,2,3-triazoles Using Click Chemistry. Synthesis 2010, 1687-1691. [CrossRef]

40. Pericherla, K.; Khedar, P.; Khungar, B.; Kumar, A. Click chemistry inspired structural modification of azole antifungal agents to synthesize novel 'drug like' molecules. Tetrahedron Lett. 2012, 53, 6761-6764. [CrossRef]

41. Nagesh, H.N.; Suresh, A.; Reddy, M.N.; Suresh, N.; Subbalakshmia, J.; Sekhar, K.V.G.C. Multicomponent cascade reaction: Dual role of copper in thesynthesis of 1,2,3-triazole tethered benzimidazo[1,2-a]quinoline and their photophysical studies. RSC Adv. 2016, 6, 15884-15894. [CrossRef]

42. Sindhu, J.; Singh, H.; Khurana, J.M.; Bhardwaj, J.K.; Saraf, P.; Sharma, C. Synthesis and biological evaluation of some functionalized 1H-1,2,3-triazole tethered pyrazolo[3,4-b]pyridin-6(7H)-ones as antimicrobial and apoptosis inducing agents. Med. Chem. Res. 2016, 25, 1813-1830. [CrossRef]

43. Fu, F.; Martínez, A.; Wang, C.; Ciganda, R.; Yate, L.; Escobar, A.; Moya, S.; Fouquet, E.; Ruiz, J.; Astruc, D. Exposure to air boosts $\mathrm{CuAAC}$ reactions catalyzed by PEG-stabilized $\mathrm{Cu}$ nanoparticles. Chem. Commun. 2017, 53, 5384-5387. [CrossRef] [PubMed]

44. Chen, J.; Spear, S.K.; Huddleston, J.G.; Rogers, R.D. Polyethylene glycol and solutions of polyethylene glycol as green reaction media. Green Chem. 2005, 7, 64-82. [CrossRef]

45. Hammond, O.S.; Bowron, D.T.; Edler, K.J. Liquid structure of the choline chloride-urea deep eutectic solvent (reline) from neutron diffraction and atomistic modelling. Green Chem. 2016, 18, 2736-2744. [CrossRef]

46. Blusztajn, J.K. Choline, a vital amine. Science 1998, 284, 794-795. [CrossRef]

47. Abbott, A.P.; Harris, R.C.; Ryder, K.S.; D’Agostino, C.; Gladden, L.F.; Mantle, M.D. Glycerol eutectics as sustainable solvent systems. Green Chem. 2011, 13, 82-90. [CrossRef]

48. Abbott, A.P.; Boothby, D.; Capper, G.; Davies, D.; Rasheed, R.K. Deep eutectic solvents formed between choline chloride and carboxylic acids: Versatile alternatives to ionic liquids. J. Am. Chem. Soc. 2004, 126, 9142-9147. [CrossRef]

49. Abbott, A.P.; Capper, G.; Davies, D.L.; Rasheed, R.K.; Tambyrajah, V. Novel solvent properties of choline chloride/urea mixtures. Chem. Commun. 2003, 70-71. [CrossRef]

50. Alonso, D.A.; Baeza, A.; Chinchilla, R.; Guillena, G.; Pastor, I.M.; Ramón, D.J. Deep Eutectic Solvents: The Organic Reaction Medium of the Century. Eur. J. Org. Chem. 2016, 612-632. [CrossRef]

51. García-Álvarez, J. Deep Eutectic Mixtures: Promising sustainable solvents for metal-catalysed and metal-mediated organic reactions. Eur. J. Inorg. Chem. 2015, 5147-5157. [CrossRef]

52. Smith, E.L.; Abbott, A.P.; Ryder, K.S. Deep eutectic solvents (DESs) and their applications. Chem. Rev. 2014, 114, 11060-11082. [CrossRef] [PubMed]

53. Illgen, F.; König, B. Organic reactions in low melting mixtures based on carbohydrates and L-carnitine-a comparison. Green Chem. 2009, 11, 848-854. [CrossRef]

54. Kafle, A.; Handy, S.T. A one-pot, copper-catalyzed azidation/click reaction of aryl and heteroaryl bromides in an environmentally friendly deep eutectic solvent. Tetrahedron 2017, 73, 7024-7029. [CrossRef]

55. Xiong, X.; Yi, C.; Liao, X.; Lai, S. A practical multigram-scale method for the green synthesis of 5-substituted-1H-tetrazoles in deep eutectic solvent. Tetrahedron Lett. 2019, 60, 402-406. [CrossRef]

56. Moses, J.E.; Moorhouse, A.D. The growing applications of click chemistry. Chem. Soc. Rev. 2007, 36, $1249-1262$. [CrossRef]

57. Kappe, C.O.; Van der Eycken, E. Click chemistry under non-classical reaction conditions. Chem. Soc. Rev. 2010, 39, 1280-1290. [CrossRef]

58. Thirumurugan, P.; Matosiuk, D.; Jozwiak, K. Click Chemistry for Drug Development and Diverse Chemical-Biology Applications. Chem. Rev. 2013, 113, 4905-4979. [CrossRef]

59. Hein, J.E.; Fokin, V.V. Copper-catalyzed azide-alkyne cycloaddition (CuAAC) and beyond: New reactivity of copper(I) acetylides. Chem. Soc. Rev. 2010, 39, 1302-1315. [CrossRef]

60. Alonso, F.; Moglie, Y.; Radivoy, G. Copper Nanoparticles in Click Chemistry. Acc. Chem. Res. 2015, 48, 2516-2528. [CrossRef]

61. Haldón, E.; Nicasio, M.C.; Pérez, P.J. Copper-Catalysed Azide-Alkyne Cycloadditions (CuAAC): An Update. Org. Biomol. Chem. 2015, 13, 9528-9550. [CrossRef] [PubMed] 
62. Hassan, S.; Müller, T.J.J. Multicomponent Syntheses based upon Copper-Catalyzed Alkyne-Azide Cycloaddition. Adv. Synth. Catal. 2015, 357, 617-666. [CrossRef]

63. Wang, K.; Bi, X.; Xing, S.; Liao, P.; Fang, Z.; Meng, X.; Zhang, Q.; Liu, Q.; Ji, Y. Cu ${ }_{2} \mathrm{O}$ acting as a robust catalyst in CuAAC reactions: Water is the required medium. Green Chem. 2011, 13, 562-565. [CrossRef]

64. Jiang, Y.; Kong, D.; Zhao, J.; Zhang, W.; Xu, W.; Li, W.; Xu, G. A simple, efficient thermally promoted protocol for Huisgen-click reaction catalyzed by $\mathrm{CuSO}_{4}-5 \mathrm{H}_{2} \mathrm{O}$ in water. Tetrahedron Lett. 2014, 55, 2410-2414. [CrossRef]

65. Jiang, Y.; Li, X.; Li, X.; Sun, Y.; Zhao, Y.; Jia, S.; Guo, N.; Xu, G.; Zhang, W. Copper(II) Acetylacetonate: An Efficient Catalyst for Huisgen-Click Reaction for Synthesis of 1,2,3-Triazoles in Water. Chin. J. Chem. 2017, 35, 1239-1245. [CrossRef]

66. Castro-Godoy, W.D.; Heredia, A.A.; Schmidt, L.C.; Argüello, J.E. A straightforward and sustainable synthesis of 1,4-disubstituted 1,2,3-triazoles via visible-light promoted copper-catalyzed azide-alkyne cycloaddition (CuAAC). RSC Adv. 2017, 7, 33967-33973. [CrossRef]

67. Li, X.; Chen, X.; Jiang, Y.; Chen, S.; Qu, L.; Qu, Z.; Yuan, J.; Shi, H. Highly Efficient Ultrasonic-Assisted CuCl-Catalyzed 1,3-Dipolar Cycloaddition Reactions in Water: Synthesis of Coumarin Derivatives Linked with 1,2,3-Triazole Moiety. J. Heterocycl. Chem. 2016, 53, 1402-1411. [CrossRef]

68. Yan, Z.-Y.; Zhao, Y.-B.; Fan, M.-J.; Liu, W.-M.; Liang, Y.-M. General synthesis of (1-substituted-1H-1,2,3triazol-4-ylmethyl)-dialkylamines via a copper(I)-catalyzed three-component reaction in water. Tetrahedron 2005, 61, 9331-9337. [CrossRef]

69. Asano, K.; Matsubara, S. Effects of a Flexible Alkyl Chain on a Ligand for CuAAC Reaction. Org. Lett. 2010, 12, 4988-4991. [CrossRef]

70. Wang, F.; Fu, H.; Jiang, Y.Y.; Zhao, Y.F. Copper-Catalyzed Cycloaddition of Sulfonyl Azides with Alkynes to Synthesize N-Sulfonyltriazoles on Water at Room Temperature. Adv. Synth. Catal. 2008, 350, 1830-1834. [CrossRef]

71. Wang, F.; Fu, H.; Jiang, Y.Y.; Zhao, Y.F. Quick and highly efficient copper-catalyzed cycloaddition of aliphatic and aryl azides with terminal alkynes "on water". Green Chem. 2008, 10, 452-456. [CrossRef]

72. Ali, A.A.; Chetia, M.; Saikia, P.J.; Sarma, D. (DHQD) ${ }_{2}$ PHAL ligand-accelerated Cu-catalyzed azide-alkyne cycloaddition reactions in water at room temperature. RSC Adv. 2014, 4, 64388-64392. [CrossRef]

73. Jiang, Y.; Kong, D.; Zhao, J.; Qi, Q.; Li, W.; Xu, Q. $\mathrm{Cu}(\mathrm{OAc})_{2} \cdot \mathrm{H}_{2} \mathrm{O} / \mathrm{NH}_{2} \mathrm{NH}_{2} \cdot \mathrm{H}_{2} \mathrm{O}$ : An efficient catalyst system that in situ generates $\mathrm{Cu}_{2} \mathrm{O}$ nanoparticles and HOAc for Huisgen click reactions. RSC Adv. 2014, 4, 1010-1014. [CrossRef]

74. Zhang, W.; Ren, B.; Jiang, Y.; Hu, Z. Carboxymethylpullulans Promoted $\mathrm{Cu}_{2} \mathrm{O}-$ Catalyzed Huisgen-Click Reaction. RSC Adv. 2015, 5, 12043-12047. [CrossRef]

75. Hein, J.E.; Tripp, J.C.; Krasnova, L.B.; Sharpless, K.B.; Fokin, V.V. Copper(I)-Catalyzed Cycloaddition of Organic Azides and 1-Iodoalkynes. Angew. Chem. Int. Ed. 2009, 48, 8018-8021. [CrossRef]

76. Li, L.; Ding, S.; Yang, Y.; Zhu, A.; Fan, X.; Cui, M.; Chen, C.; Zhang, G. Multicomponent Aqueous Synthesis of Iodo-1,2,3-triazoles: Single-Step Models for Dual Modification of Free Peptide and Radioactive Iodo Labeling. Chem. Eur. J. 2017, 23, 1166-1172. [CrossRef]

77. Lal, S.; McNally, J.; White, A.J.P.; Díez-González, S. Novel Phosphinite and Phosphonite Copper(I) Complexes: Efficient Catalysts for Click Azide-Alkyne Cycloaddition Reactions. Organometallics 2011, 30, 6225-6232. [CrossRef]

78. Lal, S.; Díez-González, S. $\left[\mathrm{CuBr}\left(\mathrm{PPh}_{3}\right)_{3}\right]$ for Azide-Alkyne Cycloaddition Reactions under Strict Click Conditions. J. Org. Chem. 2011, 76, 2367-2373. [CrossRef]

79. Díez-González, S.; Nolan, S.P. [(NHC) $\left.{ }_{2} \mathrm{Cu}\right] \mathrm{X}$ Complexes as Efficient Catalysts for Azide-Alkyne Click Chemistry at Low Catalyst Loadings. Angew. Chem. Int. Ed. 2008, 47, 8881-8884. [CrossRef]

80. Gaulier, C.; Hospital, A.; Legeret, B.; Delmas, A.F.; Aucagne, V.; Cisnettia, F.; Gautier, A. A water soluble $\mathrm{CuI-NHC}$ for CuAAC ligation of unprotected peptides under open air conditions. Chem. Commun. 2012, 48, 4005-4007. [CrossRef]

81. Díez-González, S.; Correa, A.; Cavallo, L.; Nolan, S.P. (NHC)Copper(I)-Catalyzed [3+2] Cycloaddition of Azides and Mono- or Disubstituted Alkynes. Chem. Eur. J. 2006, 12, 7558-7564. [CrossRef] [PubMed]

82. García-Álvarez, J.; Díez, J.; Gimeno, J. A highly efficient copper(i) catalyst for the 1,3-dipolar cycloaddition of azides with terminal and 1-iodoalkynes in water: Regioselective synthesis of 1,4-disubstituted and 1,4,5-trisubstituted 1,2,3-triazoles. Green Chem. 2010, 12, 2127-2130. [CrossRef] 
83. García-Álvarez, J.; Díez, J.; Gimeno, J.; Suárez, F.J.; Vincent, C. (Iminophosphorane)copper(I) Complexes as Highly Efficient Catalysts for 1,3-Dipolar Cycloaddition of Azides with Terminal and 1-Iodoalkynes in Water: One-Pot Multi-Component Reaction from Alkynes and in situ Generated Azides . J. Inorg. Chem. 2012, 35, 5854-5863. [CrossRef]

84. Özçubukçu, S.; Ozkal, E.; Jimeno, C.; Pericàs, M.A. A Highly Active Catalyst for Huisgen 1,3-Dipolar Cycloadditions Based on the Tris(triazolyl)methanol-Cu(I) Structure. Org. Lett. 2009, 11, 4682-4683. [CrossRef]

85. Ozkal, E.; Llanes, P.; Bravo, F.; Ferrali, A.; Pericàs, M.A. Fine-Tunable Tris(triazolyl)methane Ligands for Copper(I)-Catalyzed Azide-Alkyne Cycloaddition Reactions. Adv. Synth. Catal. 2014, 356, 857-869. [CrossRef]

86. Zhou, C.; Zhang, J.; Liu, P.; Xie, J.; Dai, B. 2-Pyrrolecarbaldiminato-Cu(II) complex catalyzed three-component 1,3-dipolar cycloaddition for 1,4-disubstituted 1,2,3-triazoles synthesis in water at room temperature. RSC Adv. 2015, 5, 6661-6665. [CrossRef]

87. Mahmoud, A.G.; Guedes da Silva, M.F.C.; Mahmudov, K.T.; Pombeiro, A.J.L. Arylhydrazone ligands as $\mathrm{Cu}$-protectors and -catalysis promoters in the azide-alkyne cycloaddition reaction. Dalton Trans. 2019, 48, 1774-1785. [CrossRef]

88. Szadkowska, A.; Staszko, S.; Zaorska, E.; Pawłowski, R. A theophylline based copper N-heterocyclic carbene complex: Synthesis and activity studies in green media. RSC Adv. 2016, 6, 44248-44253. [CrossRef]

89. Deraedt, C.; Pinaud, N.; Astruc, D. Recyclable Catalytic Dendrimer Nanoreactor for Part-Per-Million CuI Catalysis of "Click" Chemistry in Water. J. Am. Chem. Soc. 2014, 136, 12092-12098. [CrossRef]

90. Shin, J.-A.; Lim, Y.-G. Facile Synthesis of Glycidyl Triazolyl Polymers in Water Using $\beta$-Cyclodextrin. Bull. Korean Chem. Soc. 2015, 36, 2367-2370. [CrossRef]

91. Shin, J.-A.; Oh, S.-J.; Lee, H.-Y.; Lim, Y.-G. An efficient Cu-catalyzed azide-alkyne cycloaddition (CuAAC) reaction in aqueous medium with a zwitterionic ligand, betaine. Catal. Sci. Technol. 2017, 7, 2450-2456. [CrossRef]

92. Tasca, E.; La Sorella, G.; Sperni, L.; Strukul, G.; Scarso, A. Micellar promoted multi-component synthesis of 1,2,3-triazoles in water at room temperature. Green Chem. 2015, 17, 1414-1422. [CrossRef]

(C) 2020 by the authors. Licensee MDPI, Basel, Switzerland. This article is an open access article distributed under the terms and conditions of the Creative Commons Attribution (CC BY) license (http://creativecommons.org/licenses/by/4.0/). 